\title{
Transcriptome Analysis in the Head Kidney of Rainbow Trout (Oncorhynchus mykiss) Immunized with a Combined Vaccine of Formalin-Inactivated Aeromonas salmonicida and Vibrio anguillarum
}

\author{
Jongwon Lim (1) and Suhee Hong * \\ Department of Marine Biotechnology, Gangneung-Wonju National University, Gangneung 25457, Korea; \\ myobong@gwnu.ac.kr \\ * Correspondence: s.hong@gwnu.ac.kr; Tel.: +82-33-640-2852
}

check for updates

Citation: Lim, J.; Hong, S. Transcriptome Analysis in the Head Kidney of Rainbow Trout (Oncorhynchus mykiss) Immunized with a Combined Vaccine of Formalin-Inactivated Aeromonas salmonicida and Vibrio anguillarum. Vaccines 2021, 9, 1234. https:// doi.org/10.3390/vaccines9111234

Academic Editors: Beatriz Novoa and Patricia Pereiro

Received: 8 September 2021 Accepted: 20 October 2021 Published: 22 October 2021

Publisher's Note: MDPI stays neutral with regard to jurisdictional claims in published maps and institutional affiliations.

Copyright: (c) 2021 by the authors. Licensee MDPI, Basel, Switzerland. This article is an open access article distributed under the terms and conditions of the Creative Commons Attribution (CC BY) license (https:// creativecommons.org/licenses/by/ $4.0 /)$.

\begin{abstract}
This study aimed to identify the molecular mechanisms regulated by a combined vaccine against Aeromonas salmonicida and Vibrio anguillarum (O1 serotype). These bacteria cause furunculosis and vibriosis, respectively, and are associated with a high mortality in rainbow trout in Korea. The vaccine upregulated gene expression of $\operatorname{TCR} \alpha$, T-bet, $\operatorname{sgM}$, and $\operatorname{mIgM}$, markers of an activated adaptive immune response. On days 1,3, and 5, transcriptome analysis revealed 862 (430 up- and 432 downregulated), 492 (204 up- and 288 downregulated), and 741 (270 up- and 471 downregulated) differentially expressed genes (DEGs), respectively. Gene ontology (GO) enrichment analysis identified 377 (108 MF, 132 CC, 137 BP), 302 (60 MF, 180 CC, 62 BP), and 314 (115 MF, 129 CC, $70 \mathrm{BP}$ ) GOs at days 1, 3, and 5, respectively. Kyoto Encyclopedia of Genetic and Genomic enrichment analysis identified eight immune system-related pathways like cytokine-cytokine receptor interaction, NF-kappaB signaling pathway, TNF signaling pathway, NOD-like receptor signaling pathway, cytosolic DNA sensing pathway, cell adhesion molecule, complement and coagulation cascade, and antigen processing and presentation. In the analysis of the protein-protein interaction of immune-related DEGs, a total of 59, 21, and 21 interactional relationships were identified at days 1 , 3 , and 5, respectively, with TNF having the highest centrality at all three time points.
\end{abstract}

Keywords: vaccine; $A$. salmonicida; $V$. anguillarum; transcriptome; immune

\section{Introduction}

Rainbow trout (Oncorhynchus mykiss) is a cold-water fish popular for aquaculture worldwide due to its rapid growth rate and fertility [1]. In Korea, it is a major inland aquaculture species after eel (Anguilliformes), golden apple snail (Pomacea canaliculata), catfish (Silurus asotus), and crucian carp (Carassius carassius) [2]. Aeromonas salmonicida and Vibrio anguillarum are gram-negative bacteria associated with major diseases in Salmonids, leading to high mortality and morbidity [3,4]. A. salmonicida is the causative agent of furunculosis with symptoms of muscle ulceration, hemorrhagic sepsis, and death [4]. $V$. anguillarum causes vibriosis in Salmonids and other fish species and is one of the most frequent aquatic diseases worldwide [5]. In Korea, only serotype 1 of V. anguillarum has been isolated so far [6].

Several studies have been conducted to investigate the immune system's involvement in response to bacterial infection in rainbow trout. These studies have greatly improved our understanding of the host's immune defense mechanisms against bacterial infection. For instance, it has been demonstrated that antigen processing and presentation, phagocytosis, and cell adhesion molecules (CAMs) were activated in both the spleen and head kidney of $V$. anguillarum-infected sea bream (Pagrus major) [7]. Indeed, recent transcriptome analyses help to understand changes in host genes during host-pathogen interactions. For example, 
transcriptomic analysis was performed to study the protective response to $A$. salmonicida infection in rainbow trout fed with $\beta$-glucan [8]. In addition, transcriptome profiling was performed upon infection with $A$. salmonicida and $V$. anguillarum in rainbow trout [9]. However, most of the transcriptomics studies on $A$. salmonicida and $V$. anguillarum have focused on bacterial pathogenicity and the host's immune mechanisms after administration of live pathogens to fish.

A. salmonicida and $V$. anguillarum infections have been prevented using commercialized vaccines. An inactivated vaccine against $A$. salmonicida was developed in 1942 for oral use [10], and a vaccine against vibriosis was first published in 1964 by Hayashi et al. [11]. Since then, vaccines for both pathogens have been developed in various forms, including subunits and polyantigens, as well as in the form of DNA vaccines [12-16]. However, there is no commercialized vaccine for $A$. salmonicida and $V$. anguillarum in Korea.

Many fish vaccines are multivalent vaccines since they are beneficial for reducing handling costs. For example, Yersinia ruckeri antigens based on Danish strains were added to A. salmonicida and $V$. anguillarum vaccines to evaluate their protective efficacy [17]. In turbot (Scophthalmus maximus), a combined vaccine of attenuated V. anguillarum and Edwardsiella piscicida was found to induce a strong immune response [18]. In addition, the efficacy of multivalent formalin-killed cell vaccines against $V$. alginolyticus and $V$. parahaemolyticus was evaluated and found to be effective in Gilthead bream (Sparus aurata) [19]. A combined vaccine of inactivated Yersinia ruckeri, A. salmonicida, and V. anguillarum was observed to upregulate IL-10, IgD, and major histocompatibility complex (MHC) II gene expression. However, the sampling time point was too late to observe significant changes in the expression of other genes [17].

Microarray analysis revealed that administration of an attenuated A. salmonicida or $V$. anguillarum vaccine contributed to immune protection through the regulation of gene expression associated with antibacterial or antibody responses in Atlantic salmon (Salmo salar) [20] or zebrafish (Danio rerio) [21], respectively. In addition, comparative transcriptome analysis demonstrated a protective immune response through marked overexpression of humoral molecules in Arctic char (Salvelinus alpinus) administered with a vaccine against furunculosis [22]. However, little is known about the molecular mechanisms and signaling pathways that regulate the immune response following administration of a combination vaccine against $A$. salmonicida and $V$. anguillarum in rainbow trout.

Therefore, this study performed a transcriptome analysis to better understand the immune response in rainbow trout immunized with a combined vaccine of formalininactivated $A$. salmonicida and $V$. anguillarum. Gene expression profiles in the head kidney at days 1, 3, and 5 postvaccination were assessed by Q-PCR and RNA-seq transcript analysis.

\section{Materials and Methods}

\subsection{Fish}

Rainbow trout (Oncorhynchus mykiss) were purchased from a farm in Pyeong-Chang, Korea, and acclimated in pathogen-free conditions for a week before vaccination. Fish (average weight $33 \pm 1.3 \mathrm{~g}$ ) were kept in a continuously aerated 100-L square tank with running tap water after chlorine neutralization by addition of $2 \mathrm{ppm}$ of sodium thiosulfate pentahydrate (Daejung) and maintained at $12 \pm 1{ }^{\circ} \mathrm{C}$ [23]. Fish were treated according to GWNU's Animal Care and Use Guidelines for Animal Welfare to minimize pain during the experiment.

\subsection{Vaccine Preparation}

Highly pathogenic A. salmonicida RTDH [23] and V. anguillarum RTBHR isolated from diseased rainbow trout from farms were used for vaccine production. In shaking incubators at $180 \mathrm{rpm}$, a single colony of $A$. salmonicida RTDH or $V$. anguillarum RTBHR isolates was incubated in tryptic soy broth (TSB) at $20^{\circ} \mathrm{C}$ for $48 \mathrm{~h}$ or TSB supplemented with $2 \%$ sodium chloride at $25^{\circ} \mathrm{C}$ for $24 \mathrm{~h}$, respectively. Bacteria were inactivated in $2 \%$ formalin (Showa) for $3 \mathrm{~h}$, centrifuged at $7000 \times g$ for $25 \mathrm{~min}$, washed three times with sterile phosphate- 
buffered saline (PBS; Welgene, Gyeongsan, Korea), and adjusted to $200 \mathrm{mg} / \mathrm{mL}$ in sterile PBS. A combined vaccine (AV) was prepared by mixing equal amounts of formalin-killed A. salmonicida and $V$. anguillarum cells and stored at $4{ }^{\circ} \mathrm{C}$.

\subsection{Vaccination and Sampling}

A total of 48 fish were divided into two groups and intraperitoneally injected with $100 \mu \mathrm{L}$ of AV or sterile PBS as a negative control. At days 1,3, and 5, eight fish per group at each time point were anesthetized with 2-phenoxyethanol and sacrificed by cutting the spinal cord. Head kidneys were collected aseptically, immediately frozen in liquid nitrogen, and stored at $-70{ }^{\circ} \mathrm{C}$ until RNA isolation.

\section{4. $Q-P C R$}

Frozen head kidneys from each fish were crushed in liquid nitrogen in a mortar with a pestle, and total RNA was isolated using Qiazol (Qiagen, Hilden, Germany) according to the manufacturer's instructions [24]. The extracted RNA $(0.1-0.5 \mu \mathrm{g} / \mu \mathrm{L})$ was immediately processed for reverse transcription using RevertAid H Minus Reverse Transcriptase and random primers according to the manufacturer's instructions (Thermo Fisher Scientific). Briefly, $1 \mu \mathrm{L}$ random primer (Thermo Fisher Scientific, Waltham, MA, USA) was added to $12 \mu \mathrm{L}$ RNA and reacted at $65{ }^{\circ} \mathrm{C}$ for $5 \mathrm{~min}$. For each sample, $4 \mu \mathrm{L}$ of $5 \mathrm{X}$ Reaction Buffer Mix (Thermo), $0.5 \mu \mathrm{L}$ of RiboLock RNase inhibitor ( $20 \mathrm{U} / \mathrm{mL}$; Thermo), $2 \mu \mathrm{L}$ of $10 \mathrm{mM}$ dinucleoside triphosphate (dNTP) mix (Thermo), and $0.5 \mu \mathrm{L}$ of RevertAid H Minus Reverse Transcriptase $(100 \mathrm{U} / \mathrm{mL}$, Thermo) were added. The reaction mixture was incubated at $25^{\circ} \mathrm{C}$ for $10 \mathrm{~min}$, at $42{ }^{\circ} \mathrm{C}$ for $2 \mathrm{~h}$, and at $70^{\circ} \mathrm{C}$ for $10 \mathrm{~min}$, and the final product was diluted by adding $380 \mu \mathrm{L}$ of TE buffer.

Gene expression was analyzed by Q-PCR using the Quantstudio (Applied Biosystems, Foster City, CA, USA). Q-PCR was performed in a $20 \mu \mathrm{L}$ reaction mixture containing $10 \mu \mathrm{L}$ of SYBR Green Real-time PCR Master Mix (TaKaRa, Shiga, Japan), $0.4 \mathrm{mM}$ each for forward and reverse primers, and $4 \mu \mathrm{L}$ of cDNA using the following protocol: $10 \mathrm{~min}$ at $95^{\circ} \mathrm{C}$, template amplification for 45 cycles of denaturation for $10 \mathrm{~s}$ at $95^{\circ} \mathrm{C}$, annealing for primer specific temperature, and extension for $30 \mathrm{~s}$ at $72{ }^{\circ} \mathrm{C}$. Q-PCR was performed in duplicates and transcription levels were calculated by absolute quantitative analysis using serially diluted references [25]. In addition, data normalization was performed using a housekeeping gene, i.e., elongation factor 1-alpha.

To verify the vaccine's efficacy, the expression of adaptive immune genes, such as $\mathrm{TCR} \alpha$, T-bet, GATA3, mIgM, and sIgM, was analyzed. In addition, to validate the reliability of the RNA-seq data, nine differentially expressed genes (DEGs) were randomly selected and analyzed: heat shock protein family A (hsp70), C3, fibronectin 1, cluster of differentiation-22 (CD22), C-C motif chemokine ligand 19, hepcidin antimicrobial peptide 1 hamp-1, dnaJ heat shock protein family, and asteroid homolog 1 . Primer sequences are listed in Supplementary Table S1.

\subsection{Transcriptome Analysis \\ 2.5.1. RNA Library Construction and Mass Sequencing}

RNA library construction and sequencing of two biological replicates for the PBS group and one for the AV group at days 1,3, and 5 were performed according to the general procedure of the Illumina platform [26]. Total RNA quality and quantity were calculated using the Quant-IT RiboGreen Assay Kit (Invitrogen, Waltham, MA, USA). RNA integrity was assessed using the TapeStation RNA ScreenTape (\#5067-5576; Agilent Technologies, Santa Clara, CA, USA). A total RNA library was prepared using the TruSeq Stranded mRNA Sample Prep Kit (Illumina, San Diego, CA, USA). The cDNA library was sequenced using Illumina NovaSeq 6000 (Illumina, San Diego, CA, USA). The reliability of a small sample of RNA-seq data was verified in eight replicates at each time point in a group by assessing the expression of nine randomly selected genes by Q-PCR, as mentioned previously. 


\subsubsection{Transcriptome Annotation}

RNA-seq data were processed to obtain clean data after removing reads containing adapters or poly-N as well as low-quality reads (base quality $<20$ ). The quality of Fastq format files was evaluated using FastQC software and visually confirmed. The RNA-QCchain was used to remove low-quality reads containing adapters and poly- $\mathrm{N}$ to generate clean reads from raw reads and mapped to the Oncorhynchus mykiss reference genome (Accession No. GCF_002163495.1) using Tophat v 2.0. Clear reads were mapped to the rainbow trout reference genome (Accession No. GCF_002163495.1), and then the number and percentage of uniquely mapped reads were calculated. The known and new copies were identified in the TopHat sort results using Cufflinks v 2.1.1 [27] with optional multiread correction, frag-bias-correct, and default parameters. Expression levels were assessed by calculating the expected number of fragments per kilobase of transcript sequences per million base pairs (FPKM). The correlation between each sample was calculated through the expression value of FPKM.

\subsubsection{DEGs' Analysis}

DEG analysis was performed using Cuffdiff to compare changes between the vaccine and control groups, with multiple read correction and fragment bias correction options added for accurate analysis. Genes with FPKM ratios greater than $\log 2 \mathrm{FC}$ with a $p$-value of $<0.05$ corrected for error throughout multiple tests were considered significantly up- or downregulated, respectively, and were defined as DEGs.

DEGs were evaluated for Gene ontology (GO) enrichment analysis and Kyoto Encyclopedia of Genetic and Genomic (KEGG) pathway analysis using DAVID software to clarify the biological functions. In addition, annotations were made using a human database, as information on rainbow trout was not available in the DAVID database.

Protein-protein interactions (PPIs) were analyzed using STRING (https: / /string-db. org/, accessed on 29 August 2021), and a network for the selected DEGs was drawn using Cytoscape 3.8.2 software. Network parameters such as degree, betweenness centrality, and closeness centrality were calculated using a network analyzer in Cytoscape. On days 1, 3, and 5, the number of immunity-related genes identified by KEGG analysis was 59, 21, and 21, respectively. Moreover, we performed functional evidence-based network association predictions for a confidence score of 0.25 .

\subsection{Statistics}

Statistical analysis was performed using unpaired student's t-test to detect differences in gene expression between the AV and control groups using SPSS version 25 for Windows (IBM Inc., Armonk, NY, USA).

\section{Results}

\subsection{Effect of the Vaccine on Adaptive Immune Gene Expression}

Genes responsible for adaptive immunity were analyzed by Q-PCR. TCR $\alpha$ gene expression was significantly upregulated in the vaccinated group at days 1,3 , and 5 (Figure 1). T-bet gene expression was significantly upregulated in a time-dependent manner. On days 1 and 5, GATA3 gene expression seemed to be downregulated, but not significantly. The $\operatorname{mIgM}$ and sIgM genes were significantly upregulated at days 1,3 , and 5 . 

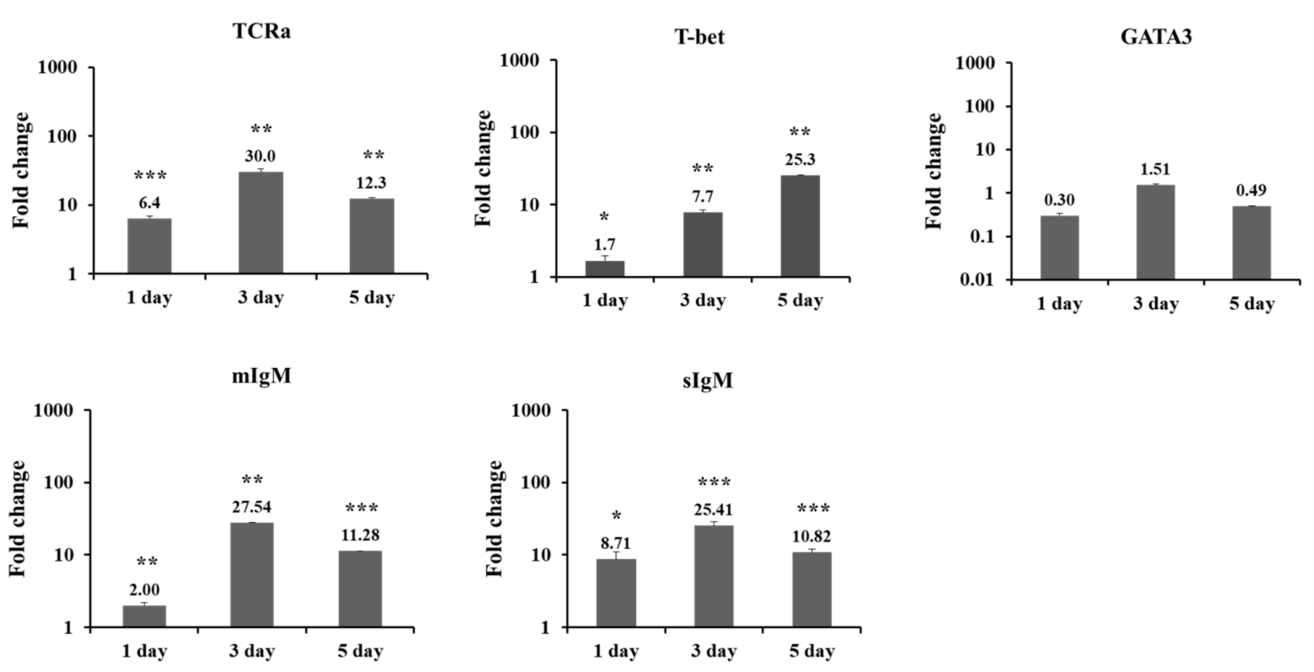

Figure 1. Q-PCR analysis of immune-related gene expression in the head kidney of rainbow trout injected with $\mathrm{AV}$ vaccine. Q-PCR data were normalized relative to the expression of the reference gene $(\mathrm{EF}-1 \alpha)$ and fold-change was calculated by dividing the ratio to EF- $1 \alpha$ by control sample at days 1,3 , and 5. Data are presented as medians \pm standard deviation (SD) $(\mathrm{n}=8)$. Asterisks $\left(^{*}\right)$ indicate significant differences $\left({ }^{*}=p<0.05,{ }^{* *}=p<0.01,{ }^{* * *}=p<0.001\right.$ ) between the PBS and AV vaccine groups.

\subsection{Transcriptome Sequencing}

After removing low-quality or duplicated reads and contaminated reads, clean reads with Q30 > 95\% and Q20 > 98\% were used for further analysis (Supplementary Table S2). Approximately $73,385,868$ to $113,451,896$ clean reads with a G/C content of approximately $48 \%$ were obtained. The unique mapping ratio of the nine transcriptome libraries of three AV- and six PBS-treated fish was more than 80\% (Supplementary Table S3).

The correlation of gene expression levels between samples was $>0.9$, as verified by the square of the Pearson correlation coefficient $\left(\mathrm{R}^{2}\right)$ (Supplementary Figure S1A). In pairwise comparisons, expression profiles between the vaccine and control groups were shown with a threshold of $-\log 10$ ( $p$-value) $\geq 1.3$ for downregulated and upregulated DEGs (Supplementary Figure S1B). Cluster analysis of DEGs indicated a difference in expression patterns between the vaccine and control groups (Supplementary Figure S1C).

\subsection{Differential Expression Analysis}

Differential expression analysis to compare the vaccinated and unvaccinated groups at days 1,3, and 5 identified 862 (430 up- and 432 downregulated), 492 (204 up- and 288 downregulated), and 741 (270 up- and 471 downregulated) DEGs with statistical significance (log2(fold-change) $>2$ and $p$-value $<0.05)$, respectively (Supplementary Table S4).

\subsection{GO Enrichment Analysis}

In GO annotations, DEGs were annotated into $377 \mathrm{GO}$ (108 MF, $132 \mathrm{CC}, 137 \mathrm{BP})$, $302 \mathrm{GO}$ (60 MF, $180 \mathrm{CC}, 62 \mathrm{BP})$, and $314 \mathrm{GO}$ (115 MF, $129 \mathrm{CC}, 70 \mathrm{BP})$ at days 1, 3 and 5 , respectively (Figure 2). On day 1, MF categories were rich in "GTP binding", "serinetype endopeptidase activity", "structural molecule activity", "receptor activity", "iron ion binding", and "collagen-binding". CC categories were rich in "cell junction", "extracellular matrix", "proteinaceous extracellular matrix", "cytoplasmic vesicle", and "external side of plasma membrane, synapse". BP categories were rich in "inflammatory response", "immune response", "extracellular matrix organization", "angiogenesis", "defense response to virus", and "tumor necrosis factor-mediated signaling pathway". 

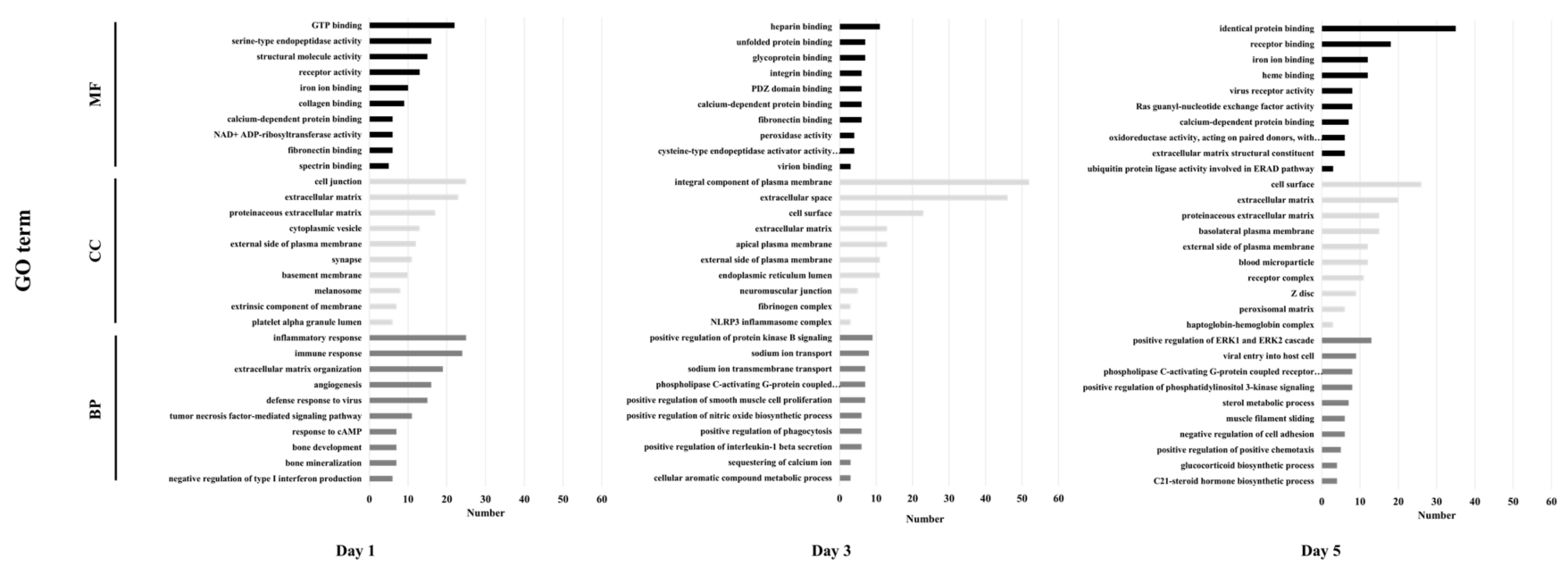

Figure 2. GO functional classification of DEGs between PBS and AV groups at days 1,3, and 5. DEGs were annotated by biological process, cellular component, and molecular function. The X-axis is the number of annotated DEGs, and the Y-axis is the top $10 \mathrm{GO}$ categories.

On day 3, MF categories were rich in "heparin-binding", "unfolded protein binding", and "glycoprotein binding". CC categories were rich in "integral component of plasma membrane", "extracellular space", "cell surface", "extracellular matrix", "apical plasma membrane", and "external side of plasma membrane". BP categories were rich in "positive regulation of protein kinase B signaling", "sodium ion transport", "sodium ion transmembrane transport", and "phospholipase C-activating G-protein coupled receptor signaling pathway", and "positive regulation of smooth muscle cell proliferation" was abundant.

On day 5, MF categories were rich in "identical protein binding", "receptor binding", "iron ion binding", and "heme binding". CC categories were rich in "cell surface", "extracellular matrix", "proteinaceous extracellular matrix", and "basolateral plasma membrane". Finally, BP categories were rich in "positive regulation of extracellular signal-regulated kinase 1 (ERK1) and ERK2 cascade", "viral entry into host cell", "phospholipase C-activating G-protein coupled receptor signaling pathway", and "positive regulation of phosphatidylinositol 3-kinase signaling".

\subsection{KEGG Pathway Enrichment Analysis}

KEGG enrichment analysis identified 23, 13, and 22 pathways significantly enriched in DEG at days 1,3, and 5, respectively (Table 1). On day 1, 177 annotated genes were grouped into 12 categories comprising 23 known KEGG pathways. The most significantly abundant KEGG pathways were "cytokine-cytokine receptor interaction", "CAMs", "neuroactive ligand-receptor interaction", and "proteoglycans in cancer". On day 3, 86 annotated genes were classified into 10 categories consisting of 13 KEGG pathways, including "proteoglycans in cancer", "CAMs", "protein processing in endoplasmic reticulum", and "influenza $\mathrm{A}^{\prime \prime}$. On day 5, 203 annotated genes were classified into 14 categories consisting of 22 KEGG pathways, and the significantly enriched pathways were "metabolic pathways", "neuroactive ligand-receptor interaction", "biosynthesis of antibiotics", and "carbon metabolism". 
Table 1. KEGG classification of differentially expressed genes (DEGs) between PBS and AV groups at days 1, 3, and 5.

\begin{tabular}{|c|c|c|c|c|c|}
\hline $\begin{array}{l}\text { Time } \\
\text { (Day) }\end{array}$ & Category & $\begin{array}{l}\text { Pathway } \\
\text { ID }\end{array}$ & Pathway Terms & $\begin{array}{l}\text { No. of } \\
\text { DEGs }\end{array}$ & $\begin{array}{l}\text { Fold En- } \\
\text { richment }\end{array}$ \\
\hline \multirow{23}{*}{ Day 1} & Signaling molecules and interaction & hsa04060 & Cytokine-cytokine receptor interaction & 16 & 2.35 \\
\hline & Signaling molecules and interaction & hsa04514 & Cell adhesion molecules (CAMs) & 15 & 3.77 \\
\hline & Signaling molecules and interaction & hsa04080 & Neuroactive ligand-receptor interaction & 14 & 1.80 \\
\hline & Cancer: overview & hsa05205 & Proteoglycans in cancer & 13 & 2.32 \\
\hline & Infectious disease: viral & hsa05164 & Influenza A & 10 & 2.05 \\
\hline & Signal transduction & hsa04064 & NF-kappa B signaling pathway & 8 & 3.28 \\
\hline & Digestive system & hsa04974 & Protein digestion and absorption & 8 & 3.24 \\
\hline & Infectious disease: viral & hsa05160 & Hepatitis C & 8 & 2.14 \\
\hline & Infectious disease: parasitic & hsa05144 & Malaria & 7 & 5.09 \\
\hline & Immune system & hsa04610 & Complement and coagulation cascades & 7 & 3.62 \\
\hline & Infectious disease: parasitic & hsa05146 & Amoebiasis & 7 & 2.35 \\
\hline & Signal transduction & hsa04668 & TNF signaling pathway & 7 & 2.33 \\
\hline & Infectious disease: parasitic & hsa05140 & Leishmaniasis & 6 & 3.01 \\
\hline & Digestive system & hsa04970 & Salivary secretion & 6 & 2.49 \\
\hline & Signaling molecules and interaction & hsa04512 & ECM-receptor interaction & 6 & 2.46 \\
\hline & Endocrine system & hsa04913 & Ovarian steroidogenesis & 5 & 3.64 \\
\hline & Carbohydrate metabolism & hsa00620 & Pyruvate metabolism & 5 & 4.46 \\
\hline & Amino acid metabolism & hsa00270 & Cysteine and methionine metabolism & 5 & 4.69 \\
\hline & Amino acid metabolism & hsa00260 & $\begin{array}{l}\text { Glycine, serine, and threonine } \\
\text { metabolism }\end{array}$ & 5 & 4.57 \\
\hline & Infectious disease: bacterial & hsa05134 & Legionellosis & 5 & 3.30 \\
\hline & Immune system & hsa04621 & NOD-like receptor signaling pathway & 5 & 3.18 \\
\hline & Lipid metabolism & hsa00590 & Arachidonic acid metabolism & 5 & 2.92 \\
\hline & Infectious disease: parasitic & hsa05143 & African trypanosomiasis & 4 & 4.32 \\
\hline \multirow{13}{*}{ Day 3} & Cancer: overview & hsa05205 & Proteoglycans in cancer & 9 & 2.13 \\
\hline & Signaling molecules and interaction & hsa04514 & Cell adhesion molecules (CAMs) & 8 & 2.67 \\
\hline & Folding, sorting, and degradation & hsa04141 & $\begin{array}{l}\text { Protein processing in the endoplasmic } \\
\text { reticulum }\end{array}$ & 8 & 2.25 \\
\hline & Infectious disease: viral & hsa05164 & Influenza A & 8 & 2.18 \\
\hline & Signal transduction & hsa04020 & Calcium signaling pathway & 8 & 2.12 \\
\hline & Infectious disease: bacterial & hsa05133 & Pertussis & 6 & 3.80 \\
\hline & Immune system & hsa04621 & NOD-like receptor signaling pathway & 6 & 5.08 \\
\hline & Immune system & hsa04623 & Cytosolic DNA sensing pathway & 6 & 4.45 \\
\hline & Nucleotide metabolism & hsa00240 & Pyrimidine metabolism & 6 & 2.82 \\
\hline & Global and overview maps & hsa01200 & Carbon metabolism & 6 & 2.52 \\
\hline & Infectious disease: bacterial & hsa05134 & Legionellosis & 5 & 4.39 \\
\hline & Amino acid metabolism & hsa00260 & $\begin{array}{l}\text { Glycine, serine, and threonine } \\
\text { metabolism }\end{array}$ & 5 & 6.08 \\
\hline & Immune system & hsa04612 & Antigen processing and presentation & 5 & 3.12 \\
\hline \multirow{22}{*}{ Day 5} & Global and overview maps & hsa01100 & Metabolic pathways & 50 & 1.43 \\
\hline & Signaling molecules and interaction & hsa04080 & Neuroactive ligand-receptor interaction & 14 & 1.76 \\
\hline & $\begin{array}{l}\text { Metabolism of terpenoids and } \\
\text { polvketides }\end{array}$ & hsa01130 & Biosynthesis of antibiotics & 13 & 2.14 \\
\hline & Global and overview maps & hsa01200 & Carbon metabolism & 12 & 3.71 \\
\hline & Signaling molecules and interaction & hsa04060 & Cytokine-cytokine receptor interaction & 12 & 1.72 \\
\hline & Lipid metabolism & hsa00140 & Steroid hormone biosynthesis & 9 & 5.42 \\
\hline & Signal transduction & hsa04064 & NF-kappa B signaling pathway & 8 & 3.21 \\
\hline & Immune system & hsa04610 & Complement and coagulation cascades & 8 & 4.05 \\
\hline & Digestive system & hsa04976 & Bile secretion & 8 & 4.05 \\
\hline & Carbohydrate metabolism & hsa00010 & Glycolysis/Gluconeogenesis & 8 & 4.17 \\
\hline & Endocrine system & hsa04922 & Glucagon signaling pathway & 7 & 2.47 \\
\hline & Infectious disease: parasitic & hsa05143 & African trypanosomiasis & 6 & 6.35 \\
\hline & Infectious disease: bacterial & hsa05134 & Legionellosis & 6 & 3.88 \\
\hline & Endocrine system & hsa04913 & Ovarian steroidogenesis & 6 & 4.28 \\
\hline & Global and overview maps & hsa01230 & Biosynthesis of amino acids & 6 & 2.91 \\
\hline & $\begin{array}{l}\text { Xenobiotics biodegradation and } \\
\text { metabolism }\end{array}$ & hsa00980 & $\begin{array}{c}\text { Metabolism of xenobiotics by cytochrome } \\
\text { P450 }\end{array}$ & 6 & 2.83 \\
\hline & $\begin{array}{c}\text { Metabolism of cofactors and } \\
\text { vitamins }\end{array}$ & hsa00760 & Nicotinate and nicotinamide metabolism & 4 & 4.82 \\
\hline & Carbohydrate metabolism & hsa00630 & $\begin{array}{l}\text { Glyoxylate and dicarboxylate } \\
\text { metabolism }\end{array}$ & 4 & 5.17 \\
\hline & Amino acid metabolism & hsa00340 & Histidine metabolism & 4 & 6.35 \\
\hline & Carbohydrate metabolism & hsa00040 & $\begin{array}{l}\text { Pentose and glucuronate } \\
\text { interconversions }\end{array}$ & 4 & 4.23 \\
\hline & Amino acid metabolism & hsa00250 & $\begin{array}{c}\text { Alanine, aspartate, and glutamate } \\
\text { metabolism }\end{array}$ & 4 & 3.99 \\
\hline & Amino acid metabolism & hsa00260 & $\begin{array}{l}\text { Glycine, serine, and threonine } \\
\text { metabolism }\end{array}$ & 4 & 3.58 \\
\hline
\end{tabular}




\subsection{PPI Analysis of DEGs}

For the PPI network analysis of DEG, 59 genes at day 1, 21 genes at day 3, and 21 genes at day 5 identified in the KEGG analysis were used. In the PPI network analysis, a total of 486, 156, and 156 interactional relationships were identified between 59, 21, and 21 genes in the DEG at days 1,3, and 5, respectively (Figure 3). The TNF gene showed the highest centrality in the centrality test at days 1, 3, and 5, followed by IL-1 $\beta$ at days 1 and 3, C 3 at day 5 (Supplementary Table S5).
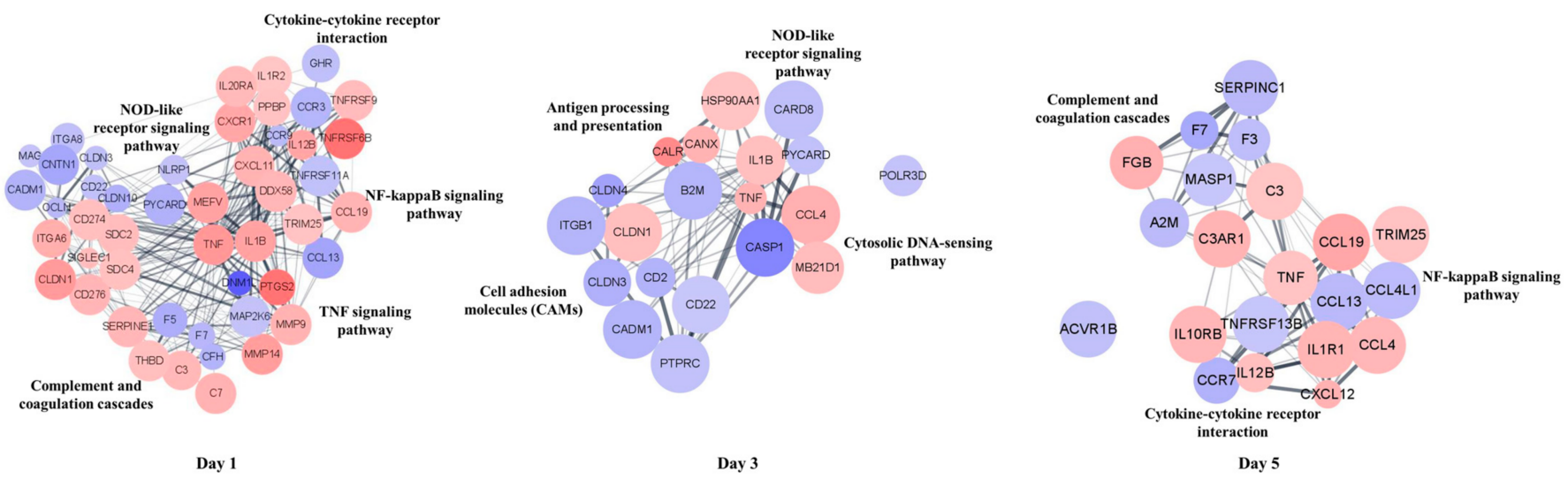

Figure 3. Protein-protein interaction (PPI) networks of immune-related DEGs at days 1, 3, and 5. Nodes represent genes, and links represent networks (genes can be linked by more than one type of network). Proteins are represented by nodes, and interactions are represented by edges. The number of edges is related to the strength of the interaction. The red and blue colors represent the upregulated and downregulated genes. The size of the node is inversely proportional to the $p$-value.

\subsection{Analysis of DEGs in Immune-Related Pathways}

A total of 75 (38 upregulated and 37 downregulated) annotated genes were identified to be involved in immune system-related KEGG pathways, including cytokine-cytokine receptor interaction, NF-kappaB signaling pathway, TNF signaling pathway, NOD-like receptor signaling pathway, cytoplasmic DNA sensing pathway, CAM, complement and coagulation cascade, and antigen processing and presentation (Table 2).

Table 2. Summary of DEGs in immune-related KEGG pathways.

\begin{tabular}{|c|c|c|c|c|c|c|}
\hline \multirow{2}{*}{$\begin{array}{l}\text { Category/Gene } \\
\text { Name }\end{array}$} & \multirow{2}{*}{ Description } & \multicolumn{5}{|c|}{ Fold-Change $/ p$-Value } \\
\hline & & & Day 1 & Day 3 & & y 5 \\
\hline \multicolumn{7}{|c|}{ Cytokine-cytokine receptor interaction } \\
\hline TNF & Tumor necrosis factor & 3.87 & 0.0016 & & 2.11 & 0.00485 \\
\hline TNFRSF11A & TNF receptor superfamily member $11 \mathrm{~A}$ & -2.18 & 0.00005 & & & \\
\hline TNFRSF13B & TNF receptor superfamily member $13 \mathrm{~B}$ & & & & -2.04 & 0.00065 \\
\hline TNFRSF6B & TNF receptor superfamily member $6 \mathrm{~B}$ & 5.39 & 0.00005 & & & \\
\hline TNFRSF9 & TNF receptor superfamily member 9 & 2.43 & 0.00005 & & & \\
\hline IL1 $\beta$ & Interleukin 1 beta & 3.46 & 0.00015 & & & \\
\hline IL10R $\beta$ & Interleukin 10 receptor subunit beta & & & & 2.63 & 0.00005 \\
\hline IL12 $\beta$ & Interleukin 12B & 3.33 & 0.0258 & & 2.26 & 0.0314 \\
\hline IL1R1 & Interleukin 1 receptor type 1 & & & & 2.73 & 0.00005 \\
\hline IL1R2 & Interleukin 1 receptor type 2 & 2.02 & 0.00005 & & & \\
\hline IL20RA & Interleukin 20 receptor subunit alpha & 2.51 & 0.00005 & & & \\
\hline CCL13 & C-C motif chemokine ligand 13 & -3.4 & 0.00005 & & -2.5 & 0.00005 \\
\hline
\end{tabular}


Table 2. Cont.

\begin{tabular}{|c|c|c|c|c|c|c|c|}
\hline \multirow{3}{*}{$\begin{array}{c}\begin{array}{c}\text { Category/Gene } \\
\text { Name }\end{array} \\
\text { CCL19 }\end{array}$} & \multirow{2}{*}{ Description } & \multicolumn{6}{|c|}{ Fold-Change/ $p$-Value } \\
\hline & & \multicolumn{3}{|c|}{ Day 1} & \multirow[t]{2}{*}{ Day 3} & \multicolumn{2}{|c|}{ Day 5} \\
\hline & C-C motif chemokine ligand 19 & 2.74 & 0.00005 & & & 3.28 & 0.00005 \\
\hline CCL4 & C-C motif chemokine ligand 4 & & & & & 2.64 & 0.00005 \\
\hline CCL4L2 & C-C motif chemokine ligand 4 like 2 & & & & & -2.43 & 0.00015 \\
\hline CCR3 & C-C motif chemokine receptor 3 & -2.68 & 0.00005 & & & & \\
\hline CCR7 & C-C motif chemokine receptor 7 & & & & & -2.85 & 0.0189 \\
\hline CCR9 & C-C motif chemokine receptor 9 & -2.48 & 0.046 & & & & \\
\hline CXCL11 & C-X-C motif chemokine 11 & 2.78 & 0.00115 & & & & \\
\hline CXCL12 & C-X-C motif chemokine ligand 12 & & & & & 2.83 & 0.0495 \\
\hline CXCR1 & $\mathrm{C}-\mathrm{X}-\mathrm{C}$ motif chemokine receptor 1 & 3.29 & 0.0005 & & & & \\
\hline ACVR1B & Activin A receptor type $1 \mathrm{~B}$ & & & & & -2.23 & 0.0009 \\
\hline GHR & Growth hormone receptor & -2.25 & 0.0072 & & & & \\
\hline РPBP & Pro-platelet basic protein & 2.16 & 0.00855 & & & & \\
\hline \multicolumn{8}{|c|}{ NF-kappaB signaling pathway } \\
\hline TNF & Tumor necrosis factor & 3.87 & 0.0016 & & & 2.11 & 0.00485 \\
\hline $\begin{array}{l}\text { TNFRSF11A } \\
\text { (RANK) }\end{array}$ & TNF receptor superfamily member $11 \mathrm{~A}$ & -2.18 & 0.00005 & & & & \\
\hline IL1 $\beta$ & Interleukin 1 beta & 3.46 & 0.00015 & & & & \\
\hline IL1R1 & Interleukin 1 receptor type 1 & & & & & 2.73 & 0.00005 \\
\hline CXCL12 & $\mathrm{C}-\mathrm{X}-\mathrm{C}$ motif chemokine ligand 12 & & & & & 2.83 & 0.0495 \\
\hline CCL4L2 & C-C motif chemokine ligand 4 like 2 & & & & & -2.43 & 0.00015 \\
\hline CCL4 & C-C motif chemokine ligand 4 & & & & & 2.64 & 0.00005 \\
\hline CCL19 & C-C motif chemokine ligand 19 & 2.74 & 0.00005 & & & 3.28 & 0.00005 \\
\hline CCL13 & $\mathrm{C}-\mathrm{C}$ motif chemokine ligand 13 & -3.4 & 0.00005 & & & -2.5 & 0.00005 \\
\hline TRIM25 & Tripartite motif-containing 25 & 2.09 & 0.00005 & & & 2.15 & 0.00015 \\
\hline PTGS2 & Prostaglandin-endoperoxide synthase 2 & 5.34 & 0.01175 & & & & \\
\hline DDX58 (RIG-I) & DExD/H-Box Helicase 58 & 2.62 & 0.00005 & & & & \\
\hline \multicolumn{8}{|c|}{ TNF signaling pathway } \\
\hline TNF & Tumor necrosis factor & 3.87 & 0.0016 & & & & \\
\hline IL1 $\beta$ & Interleukin 1 beta & 3.46 & 0.00015 & & & & \\
\hline PTGS2 & Prostaglandin-endoperoxide synthase 2 & 5.34 & 0.01175 & & & & \\
\hline MMP9 & Matrix metalloproteinase- 9 & 2.81 & 0.00005 & & & & \\
\hline MMP14 & Matrix metallopeptidase 14 & 3.65 & 0.00005 & & & & \\
\hline $\begin{array}{l}\text { MAP2K6 } \\
(\mathrm{MKK6})\end{array}$ & Mitogen-activated protein kinase kinase 6 & -2.15 & 0.00005 & & & & \\
\hline DNM1L (Drp1) & Dynamin 1 Like & -6.23 & 0.03775 & & & & \\
\hline \multicolumn{8}{|c|}{ NOD-like receptor signaling pathway } \\
\hline TNF & Tumor necrosis factor & 3.87 & 0.0016 & 2.82 & 0.03365 & & \\
\hline IL1 $\beta$ & Interleukin 1 beta & 3.46 & 0.00015 & 2.34 & 0.01225 & & \\
\hline PYCARD (ASC) & $\begin{array}{l}\text { Apoptosis-associated speck-like protein } \\
\text { containing a CARD }\end{array}$ & -2.89 & 0.00005 & -2.18 & 0.02475 & & \\
\hline
\end{tabular}


Table 2. Cont.

\begin{tabular}{|c|c|c|c|c|c|c|c|}
\hline \multirow{2}{*}{$\begin{array}{l}\text { Category/Gene } \\
\text { Name }\end{array}$} & \multirow{2}{*}{ Description } & \multicolumn{6}{|c|}{ Fold-Change/ $p$-Value } \\
\hline & & & Day 1 & & Day 3 & & Day 5 \\
\hline NLRP1 & NLR family pyrin domain containing 1 & -2.16 & 0.0259 & & & & \\
\hline MEFV (Pyrin) & MEFV innate immunity regulator, pyrin & 3.43 & 0.00005 & & & & \\
\hline $\begin{array}{l}\text { HSP90AA1 } \\
\text { (Hsp90) }\end{array}$ & $\begin{array}{l}\text { Heat shock protein } 90 \text { alpha family class A } \\
\text { member } 1\end{array}$ & & & 2.06 & 0.00005 & & \\
\hline CARD8 & $\begin{array}{c}\text { Caspase recruitment domain family } \\
\text { member } 8\end{array}$ & & & -2.25 & 0.00005 & & \\
\hline \multicolumn{8}{|c|}{ Cytosolic DNA sensing pathway } \\
\hline IL1 $\beta$ & Interleukin 1 beta & & & 2.34 & 0.01225 & & \\
\hline CCL4 & $\mathrm{C}-\mathrm{C}$ motif chemokine ligand 4 & & & 2.92 & 0.00005 & & \\
\hline CASP1 & Caspase 1 & & & -4.55 & 0.00035 & & \\
\hline PYCARD (ASC) & $\begin{array}{l}\text { Apoptosis-associated speck-like protein } \\
\text { containing a CARD }\end{array}$ & & & -2.18 & 0.02475 & & \\
\hline $\begin{array}{l}\text { POLR3D (RNA } \\
\text { pol III) }\end{array}$ & RNA polymerase III Subunit D & & & -2.08 & 0.02185 & & \\
\hline MB21D1(cGAS) & Cyclic GMP-AMP Synthase & & & 2.35 & 0.0078 & & \\
\hline \multicolumn{8}{|c|}{ Cell adhesion molecules (CAMs) } \\
\hline CD2 & Cluster of differentiation 2 & & & -2.81 & 0.024 & & \\
\hline CD22 & Cluster of differentiation 22 & -2.18 & 0.03475 & -2.02 & 0.001 & & \\
\hline CD274 & Cluster of differentiation 274 & 2.32 & 0.00005 & & & & \\
\hline CD276 & Cluster of differentiation 276 & 2.69 & 0.0001 & & & & \\
\hline CLDN1 & Claudin 1 & 3.78 & 0.00005 & 2.25 & 0.0005 & & \\
\hline CLDN10 & Claudin 10 & -2.96 & 0.03065 & & & & \\
\hline CLDN3 & Claudin-3 & -2.24 & 0.03815 & -2.87 & 0.0136 & & \\
\hline CLDN4 & Claudin 4 & & & -3.49 & 0.0321 & & \\
\hline CNTN1 & Contactin 1 & -3.33 & 0.00125 & & & & \\
\hline CADM1 & Cell adhesion molecule 1 & -2.81 & 0.00005 & -2.66 & 0.00005 & & \\
\hline ITGA6 & Integrin subunit alpha 6 & 2.97 & 0.00565 & & & & \\
\hline ITGA8 & Integrin subunit alpha 8 & -2.28 & 0.01655 & & & & \\
\hline ITGB1 & Integrin beta- 1 & & & -2.73 & 0.00005 & & \\
\hline MAG & Myelin associated glycoprotein & -2.09 & 0.0414 & & & & \\
\hline OCLN & Occludin & -2.57 & 0.0476 & & & & \\
\hline PTPRC & Protein tyrosine phosphatase receptor type C & & & -2.16 & 0.00005 & & \\
\hline SDC2 & Syndecan 2 & 2.4 & 0.00005 & & & & \\
\hline SDC4 & Syndecan 4 & 2.21 & 0.00005 & & & & \\
\hline SIGLEC1 & Sialic acid-binding Ig like lectin 1 & 2.41 & 0.04695 & & & & \\
\hline \multicolumn{8}{|c|}{ Complement and coagulation cascades } \\
\hline C3 & Complement C3 & 2.57 & 0.0036 & & & 2.06 & 0.00005 \\
\hline C3AR1 & Complement C3a receptor 1 & & & & & 2.74 & 0.00005 \\
\hline $\mathrm{C} 7$ & Complement C7 & 2.85 & 0.00005 & & & & \\
\hline CFH (Factor H) & Complement factor $\mathrm{H}$ & -2.75 & 0.0349 & & & & \\
\hline
\end{tabular}


Table 2. Cont

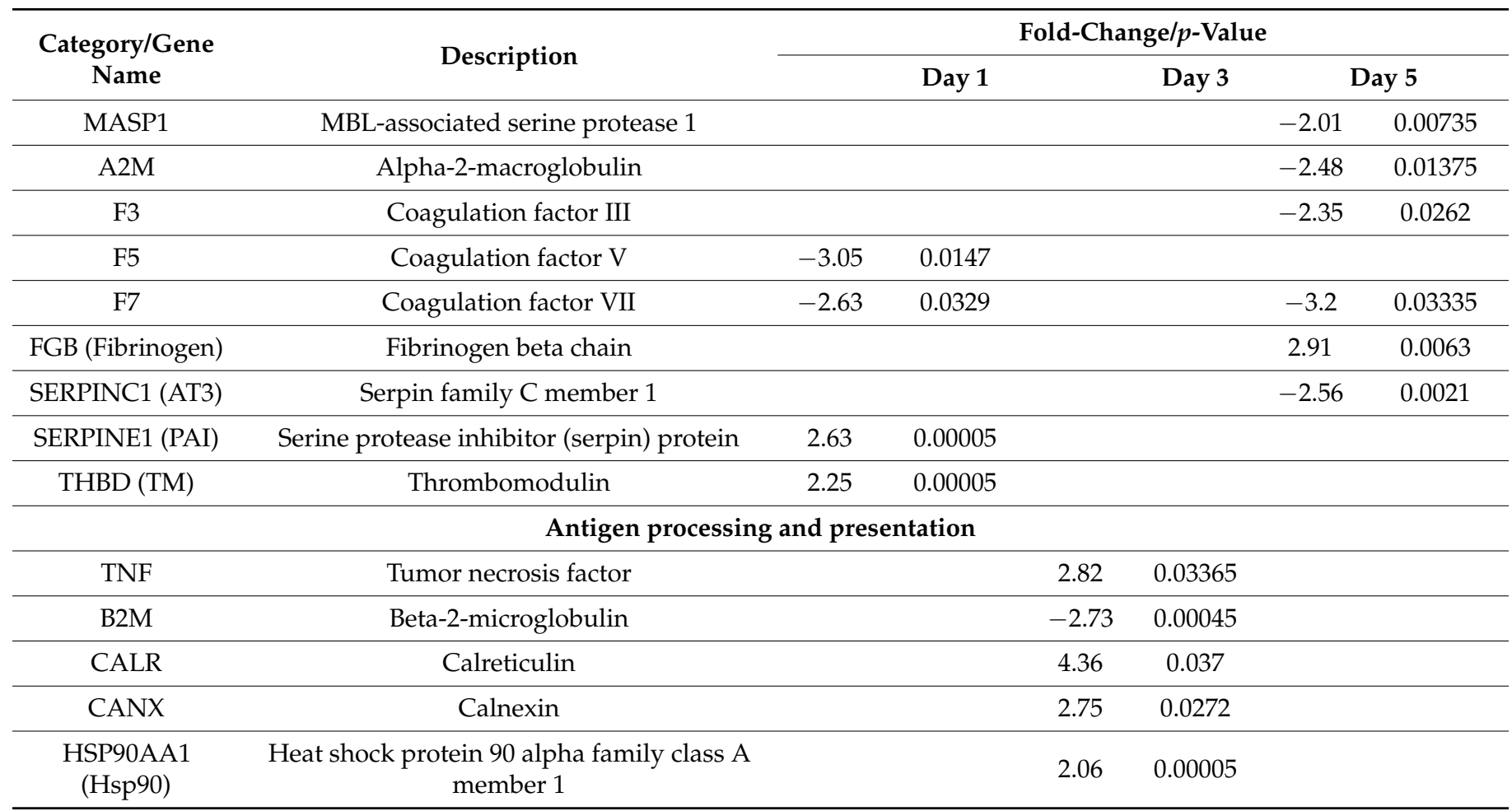

\subsection{Validation of RNA-seq Results}

The reliability of RNA-seq data was validated as nine gene expression patterns were similar to Q-PCR data from eight fish samples per group at each time point (Figure 4a). Furthermore, the correlation between the transcriptome and Q-PCR data was 0.7635 in PBS vs. AV (Figure 4b).

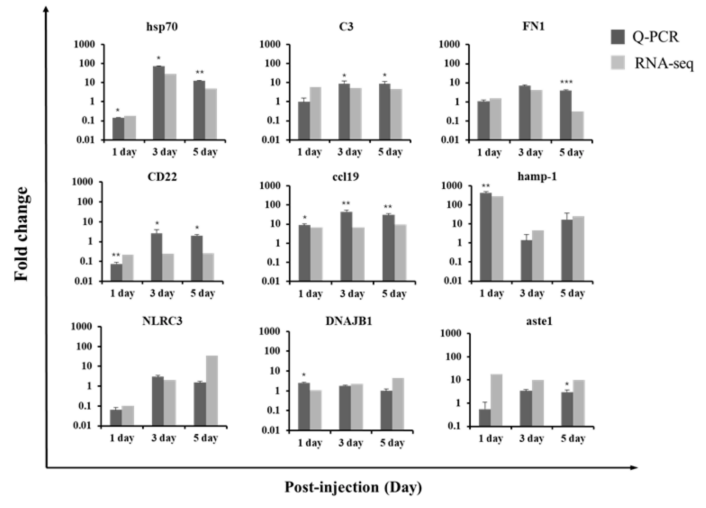

(a)

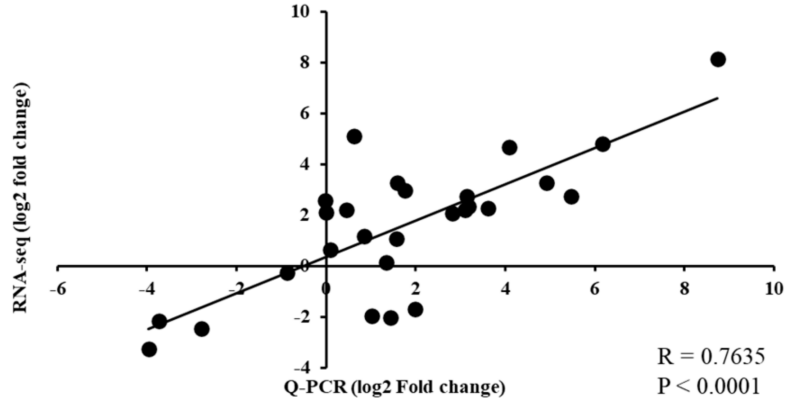

(b)

Figure 4. Validation of RNA-seq data. (a) Comparison of the fold-change of the expression of nine selected DEGs as determined by Illumina NovaSeq sequencing and Q-PCR. The DEGs were amplified in the head kidney of rainbow trout injected with AV vaccine. EF-1 $\alpha$ was used as an internal reference gene. Data are presented as medians \pm SD ( $n=8$ ). Asterisks $\left(^{*}\right)$ indicate significant differences $\left({ }^{*}=p<0.05,{ }^{* *}=p<0.01,{ }^{* * *}=p<0.001\right)$ between the PBS and AV vaccine groups. Hsp70, heat shock protein 70. C3, complement C3; FN1, fibronectin 1; CD22, cluster of differentiation 22; ccl19, C-C motif chemokine ligand 19; hamp-1, hepcidin antimicrobial peptide 1; NLRC3, NLR family CARD domain containing 3; DNAJB1, DnaJ homolog subfamily B member 1; aste1, asteroid homolog 1. (b) Correlation analysis of RNA-seq and Q-PCR in gene expression. 


\section{Discussion}

Numerous reports indicate that vaccines against A. salmonicida and $V$. anguillarum play an important role during bacterial infection in rainbow trout. In addition, it is known that vaccination using the injection route already shows an excellent protective effect [28]. Indeed, a correlation between protection and antibody titer has been demonstrated [28]. Furthermore, the various expression levels of $\mathrm{T}$ cells, transcription factors, or cytokines presented in infection studies of $A$. salmonicida and V. anguillarum provided basic information on the immune mechanism of the host's response [29,30]. In addition, recent studies on transcriptome have provided an insight into the immune response during bacterial infection in fish. However, little is known about the pathways regulating the initial immune response administration after administering the combination vaccine against $A$. salmonicida and $V$. anguillarum. Therefore, in this study, RNA-seq transcript analysis was performed in the head kidney at days 1,3, and 5 after vaccination to better understand the initial immune response of rainbow trout immunized with the mixed vaccine.

In this study, the $\mathrm{AV}$ vaccine was confirmed to have induced adaptive immunity in the head kidney, as TCR $\alpha$, T-bet, $\operatorname{mIgM}$, and sIgM genes were all upregulated in the vaccinated group. Upregulation of TCR $\alpha$ and T-bet indicates the activation of T cells, which recognize peptides presented by MHC via TCRs and initiate the adaptive immune response [31]. T-bet is a transcriptional regulator for Th- 1 differentiation and interferon- $\gamma$ production [32,33]. In this study, GATA3 gene expression seemed to be downregulated, but not significantly. Though GATA3 is a major transcription factor that regulates Th-2 differentiation [32,33], humoral immunity was also activated as the expression of mIgM and sIgM genes was significantly upregulated at days 1,3, and 5. According to a previous study, T-bet and GATA3 genes were hardly expressed in the head kidney of rainbow trout infected with A. salmonicida at days 1, 2, and 5 [29]. Previously, recognition of inactivated A. salmonicida in rainbow trout has been shown to increase IgM-positive B cells [34].

In this study, the transcriptome of rainbow trout was characterized after the administration of the $\mathrm{AV}$ vaccine for the first time. The greatest changes in gene expression were found at day 1 , and the most downregulated genes were found at day 5 . In addition, eight immune system-related KEGG pathways, including cytokine-cytokine receptor interaction, NF-kappaB signaling pathway, TNF signaling pathway, NOD-like receptor signaling pathway, cytosolic DNA sensing pathway, CAM, complement and coagulation cascade, and antigen processing and presentation, were identified. These pathways are suggested to play an important role in the vaccine's immune response of rainbow trout (Figure 5). Thus, it can be postulated that the vaccine was recognized by immune cells in the head kidney and initially activated cytokine-cytokine receptor interactions, subsequently enhancing transcription of immune genes and inflammatory factors through downstream pathways such as NF-kappaB and TNF signaling pathways. These are known to regulate many genes involved in various immune and inflammatory responses [35].

Inflammation acts as the first step in immune regulation against infection or stimuli [36]. In particular, proinflammatory cytokines, such as IL-1 and TNF $\alpha$, act as important defense mechanisms against pathogens [36]. In our study, the combined vaccine upregulated IL- $1 \beta$ and TNF $\alpha$ gene expressions at days 1 and 3, or at days 1,3, and 5. Recently, juvenile rainbow trout immunized with a multivalent vaccine combining A. salmonicida, $V$. anguillarum (O1, O2a), and Y. ruckeri (O1 biotypes 1 and 2) showed significant gene expression changes in the liver and spleen [17]. In particular, the spleen of vaccinated fish showed the most remarkable change in SAA produced by inflammatory cytokines IL-1b, IL-6, and TNF $\alpha$ after 8 weeks of vaccination [17]. In earlier studies, V. anguillarum infection was shown to result in a significant upregulation of IL-1 $\beta$ in teleosts, including Atlantic cod (Gadus morhua), gilthead seabream (Sparus aurata), and European sea bass (Dicentrarchus labrax) [37-39]. Furthermore, IL-1 $\beta$ and TNF act synergistically, with TNF being the first cytokine to follow IL-1 $\beta$ surge in the inflammatory response [40]. Therefore, administering rainbow trout with the mixed vaccine initially triggers the production of infectious cytokines such as TNF and IL-1 $\beta$ and can produce acute proteins. However, although 
NF- $\mathrm{kB}$ is known to be involved in inflammasome regulation [41], inflammasome-related genes (NLRP1, ASC, and CARD8) were downregulated at days 1 and 3 in these experiments. The inflammasome is a cytoplasmic multiprotein that senses a variety of stimuli and regulates homeostasis [42]. NLRP1, ASC, and CARD8 form an inflammasome complex that is normally inactive until activated by pathogen-associated molecular patterns and damage-associated molecular patterns and induces innate immunity [43]. In mammals, this complex stimulates the activation of caspase- 1 , the most important inflammatory protease responsible for the formation and secretion of potent proinflammatory cytokines, such as IL-1 $\beta$ [44].

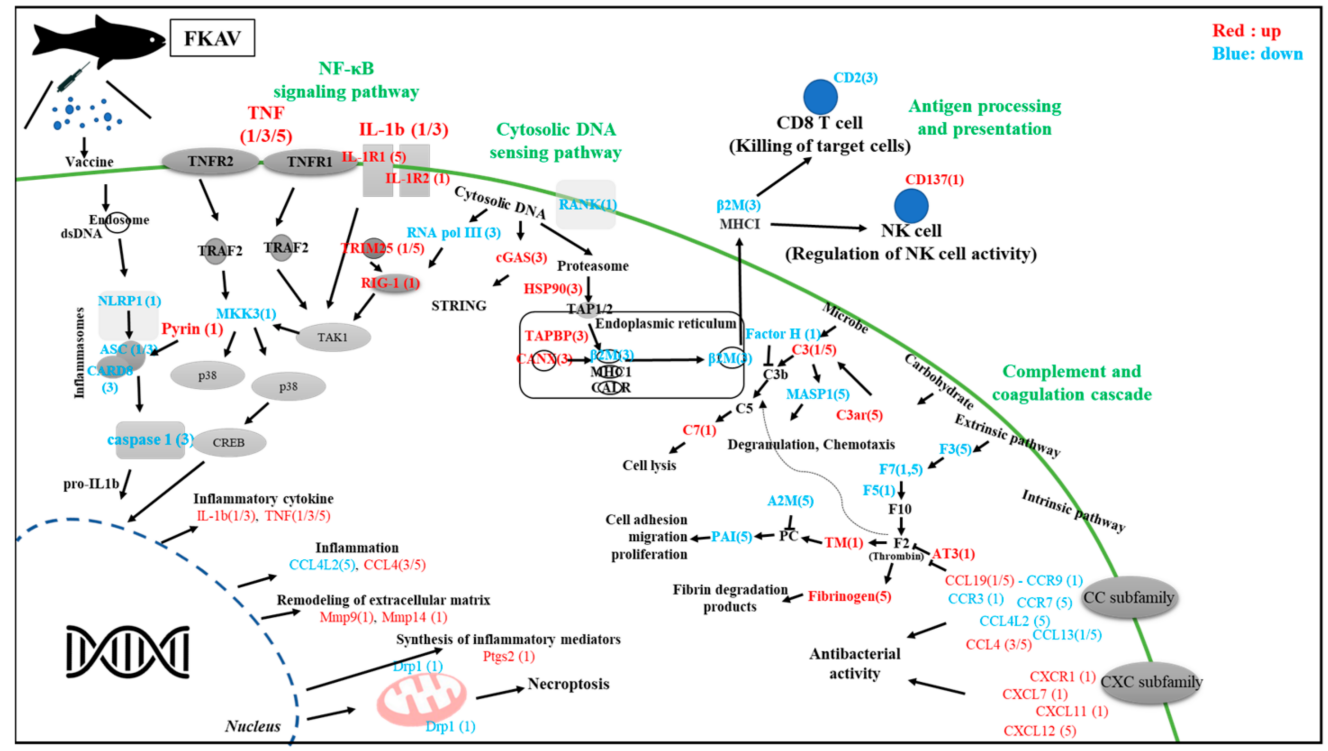

Figure 5. Presentation of putative immune pathways at days 1, 3, and 5 in AV group. DEGs regulated by $A V$ vaccine are shown in red (upregulated) or blue (downregulated). The number next to the gene indicates the time point of reaction. Black arrows show activation and regulatory responses of downstream pathways.

Caspases in mammals are classified into apoptosis initiators and inflammatory caspases according to their function [45]. In particular, casp1, casp4, casp5, casp11, and casp12 are representative inflammatory caspases [9]. Previous studies have identified a total of 18 caspase genes in the genome of rainbow trout and observed that the subfamily of inflammatory caspase contains only casp1a and casp1b [9]. In this study, caspase 1 gene expression was downregulated at day 3 . Although sea bass and avian IL-1 $\beta$ are specifically cleaved by caspase- 1 at phylogenetically conserved aspartates, distinct from the cleavage site of mammalian IL-1 $\beta$ [44], it is not clear whether downregulated caspase 1 gene expression affected IL- $1 \beta$ activity in this study. The precise function of caspase 1 in the processing of IL- $1 \beta$ in rainbow trout remains to be elucidated in more detail.

The internalized vaccine can be recognized by the cytosolic DNA sensing pathway as cyclic GMP-AMP synthase (cGAS) that was upregulated at day 3 . The cGAS catalyzes cyclic GMP-AMP (cGAMP) synthesis, and cGAMP has been identified as the only universal cytoplasmic DNA sensor in various cell types that detects double-stranded DNA [46]. Recently, a cGAS-like gene was cloned in Grass carp (Ctenopharyngodon idellus) and found to be a negative modulator for IFN reactions by targeting the stimulator of interferon genes 1 (String1) [47]. The RPC6 gene, which recognizes cytosolic DNA, was downregulated on day 3 . In addition, downstream pathway genes, tripartite motif-containing 25 (TRIM25), and retinoic acid-inducible gene (RIG)-I were upregulated at day $1 / 5$ and day 1 , respectively. RIG-I and TRIM25 are important initiators of the early immune response to viral infection [46]. RIG-I is a cytosolic pattern recognition receptor responsible for the type-1 interferon (IFN1) response [46]. RIG-I of zebrafish participates in the innate immune 
pathway similar to that of mammalian homologs [48]. It is also known that RNApol III can induce type I IFN through the RIG-I-like receptor signaling pathway [49], but RNApol III was downregulated at day 3 in this study. Thus, upregulation of cGAS and downregulation of RNA pol III at day 3 may lead to neutralization of IFN, which was activated by RIG-I and TRIM25 at day 1.

It can be assumed that the internalized antigens were processed for antigen presentation. In this study, hsp90, TAP-binding protein (TAPBP), calnexin (CANX), and beta-2-microglobulin (B2M) genes were upregulated and are known to be involved in signaling pathways for antigen processing and presentation. In a previous study, the spleen of rainbow trout stimulated with $\beta$-glucan was initially rich in antigen processing and presentation pathways, such as b2m, hsp90, and MHC1 due to A. salmonicida infection, and was involved in signaling T-cell receptors [8]. In addition, turbot administered with attenuated vaccines against Vibrio anguillarum and Edwardsiella piscicida increased adaptive immunity-related genes such as MHC I, MHC II, and TCR on day 1 after vaccination [18]. Antigens are processed and presented to specific lymphocytes after binding to MHC I or II [50]. Along with antigen presentation, CD137 gene expression was upregulated. This gene is expressed in activated T cells, dendritic cells, B cells, NK cells, neutrophils, and macrophages [51]. Crosslinking CD137 to CD137L on antigen-presenting cells increases T-cell proliferation, IL-2 secretion, survival, and cytolytic activity, indicating that it may also have triggered an antigen-specific immune response [51]. Therefore, the mixed vaccine may have prompted the head kidney of rainbow trout to first capture antigens and then deliver them to antigen-presenting cells.

In the chemokine pathway, four CXC subfamily members, CXCL7, CXCL11, CXCL12, and CXCR1, were upregulated, whereas six CC subfamily members showed variable expression patterns since CCL 4 and 19 were upregulated but CCL4L2, CCL 13, CCR7, and CCR9 were downregulated. CC and CXC chemokines have been identified in the teleost and have potential roles in homeostasis, signaling, inflammation, and immune activity [52,53]. In mammals, chemokines are among the more commonly used adjuvants for vaccination because they attract immune cells into the vaccinated site [54]. The coagulation cascade is key in maintaining hemostasis, and its activation can prevent blood loss in damaged vessels as well as repair vessels during inflammation [55]. In this study, F3 formed a complex with F7 and activated F10, but it was downregulated on day 1 and day 5 . The primary function of this system is not to neutralize invading pathogens, but to maintain the integrity of the circulatory system in the event of injury [55].

The complement system promotes the ability to clear pathogens through opsonization, phagocytosis, and B cell activation [56,57]. It is an important part of innate immunity and is significantly upregulated in response to bacteria in several teleosts, including rainbow trout, catfish (Silurus meridionalis), and grass carp (Ctenopharyngodon idella) [58-60]. The $\mathrm{C} 3$ and $\mathrm{C} 7$ genes are conserved in rainbow trout and contain several complement components [61]. MBL-associated serine protease (MASP) is a proteolytic enzyme that activates the mammalian complement system through the lectin pathway [62]. Our study showed the $\mathrm{C} 3$ gene was upregulated by days 1 and 5 , and biological relevance was also high in the PPI network analysis. Furthermore, the C7 gene was upregulated on day 1 and the MASP1 was downregulated on day 5. A previous study found that the gene expression of $\mathrm{C} 3$ was upregulated in the liver of rainbow trout immunized with a multivalent vaccine combining A. salmonicida, V. anguillarum (O1, O2a), and Y. ruckeri (O1 biotypes 1 and 2) [17]. The head kidney and spleen of rainbow trout with severe symptoms due to $V$. anguillarum infection showed a downregulated complement cascade and decreased defense against pathogen infection [63]. In addition, the expression of c1ql2, C3, C5, C7, C9, CFB, and complement factor $\mathrm{H}(\mathrm{CFH})$ was regulated in rainbow trout stimulated with $\beta$-glucan upon infection with $A$. salmonicida, suggesting improved immune enhancement [8]. Recently, Arctic Charr, a salmonid fish, showed marked significant overexpression of innate humoral molecules when a commercial furunculosis vaccine was administered [22]. 


\section{Conclusions}

This study suggests that the combination vaccine activated immune pathways that are important in the early immune responses of rainbow trout. In particular, activating the complement system, chemokines, and inflammatory cytokines activated immune responses through downstream signaling pathways. Upregulation of hsp90, TAPBP, and CANX genes induced the antigen processing and presentation pathway so that $\mathrm{T}$ cells can recognize the presence of a vaccine and trigger an immune response. Furthermore, the combined vaccine elicited a cell-mediated and humoral immune response, as evidenced by upregulated $\mathrm{TCR} \alpha$, T-bet, and IgM gene expression. This is the first report of a combination vaccine administered to rainbow trout to the best of our knowledge. This study enhances our understanding of immunity that occurs in response to a combined vaccine composed of $A$. salmonicida and $V$. anguillarum, and it lays the foundation for improving vaccine formulations in the future.

Supplementary Materials: The following are available online at https:/ / www.mdpi.com/article/10 .3390 /vaccines 9111234 /s1. Figure S1: Quality assessment and comparisons of transcriptome data quality between PBS and AV groups. Table S1: Primers used for Q-PCR. Table S2: Summary statistics for the sequencing data on nine samples. Table S3: Statistics of clean reads mapped onto reference genome. Table S4: Comparative analysis of DEG between PBS and AV. Table S5: Top 10 nodes for PPI network centrality analysis of immune-related DEGs.

Author Contributions: Conceptualization, J.L. and S.H.; methodology, J.L.; software, J.L.; validation, J.L, and S.H.; formal analysis, J.L.; investigation, J.L.; resources, S.H.; data curation, J.L.; writingoriginal draft preparation, J.L.; writing - review and editing, S.H.; visualization, J.L.; supervision, S.H.; project administration, S.H.; funding acquisition, S.H. All authors have read and agreed to the published version of the manuscript.

Funding: 'Gangwon Sea Grant Program', funded by the Ministry of Oceans and Fisheries, Korea.

Institutional Review Board Statement: The study was conducted according to the GWNU's Animal Care and Use Guidelines and approved by Institutional animal care and use committee (protocol code: GWNU-2019-20; date of approval: 17 July 2019).

Informed Consent Statement: Not applicable.

Data Availability Statement: The data that support the findings of this study are available from the corresponding author upon reasonable request.

Acknowledgments: This research was a part of the project titled 'Gangwon Sea Grant Program', funded by the Ministry of Oceans and Fisheries, Korea.

Conflicts of Interest: There is no conflict of interest.

\section{References}

1. Aksnes, A.; Hope, B.; Jönsson, E.; Bjornsson, B.T.; Albrektsen, S. Size-fractionated fish hydrolysate as feed ingredient for rainbow trout (Oncorhynchus mykiss) fed high plant protein diets. I: Growth, growth regulation and feed utilization. Aquaculture 2006, 261, 305-317. [CrossRef]

2. Korean Statistical Information Service. Available online: http://kosis.kr/eng/ (accessed on 19 August 2021).

3. Menanteau-Ledouble, S.; Kumar, G.; Saleh, M.; El-Matbouli, M. Aeromonas salmonicida: Updates on an old acquaintance. Dis. Aquat. Org. 2016, 120, 49-68. [CrossRef]

4. Frans, I.; Michiels, C.; Bossier, P.; Willems, K.A.; Lievens, B.; Rediers, H. Vibrio anguillarum as a fish pathogen: Virulence factors, diagnosis and prevention. J. Fish Dis. 2011, 34, 643-661. [CrossRef] [PubMed]

5. Dallaire-Dufresne, S.; Tanaka, K.H.; Trudel, M.V.; Lafaille, A.; Charette, S.J. Virulence, genomic features, and plasticity of Aeromonas salmonicida subsp. salmonicida, the causative agent of fish furunculosis. Veter. Microbiol. 2014, 169, 1-7. [CrossRef]

6. Cheon, H.; Kim, W.; Cho, M.; Jeong, S.; Han, H. Characteristics of Vibrio anguillarum Isolated from Seawater Cultured Rainbow Trout Oncorhynchus mykiss in Korea. Fish. Aquat. Sci. 2018, 51, 254-261.

7. Song, L.; Dong, X.; Hu, G. Transcriptome analysis of red sea bream (Pagrus major) head kidney and spleen infected by Vibrio anguillarum. Aquac. Rep. 2021, 21, 100789. [CrossRef]

8. Ji, L.; Sun, G.; Li, X.; Liu, Y. Comparative transcriptome analysis reveals the mechanism of $\beta$-glucan in protecting rainbow trout (Oncorhynchus mykiss) from Aeromonas salmonicida infection. Fish Shellfish Immunol. 2019, 98, 87-99. [CrossRef] 
9. Zeng, C.; Hou, Z.S.; Zhao, H.K.; Xin, Y.R.; Liu, M.Q.; Yang, X.D.; Li, J.F. Identification and characterization of caspases genes in rainbow trout (Oncorhynchus mykiss) and their expression profiles after Aeromonas salmonicida and Vibrio anguillarum infec-tion. Dev. Comp. Immunol. 2021, 118, 103987. [CrossRef]

10. Duff, D.C.B. The oral immunization of trout against Bacterium salmonicida. J. Immunol. 1942, 44, 87-94.

11. Hayashi, K.; Kobayashi, S.; Kamata, T.; Ozaki, H. Studies on the vibrio disease of rainbow trout. II. Prophylactic vaccination against the vibrio disease. J. Fac. Fish. Pref. Univ. Mie 1964, 6, 181-191.

12. Marana, M.H.; Jørgensen, L.V.G.; Skov, J.; Chettri, J.K.; Mattsson, A.H.; Dalsgaard, I.; Kania, P.W.; Buchmann, K. Subunit vaccine candidates against Aeromonas salmonicida in rainbow trout Oncorhynchus mykiss. PLoS ONE 2017, 12, e0171944. [CrossRef]

13. Torres-Corral, Y.; Girons, A.; González-Barreiro, O.; Seoane, R.; Riaza, A.; Santos, Y. Effect of Bivalent Vaccines against Vibrio anguillarum and Aeromonas salmonicida Subspecie achromogenes on Health and Survival of Turbot. Vaccines 2021, 9, 906. [CrossRef] [PubMed]

14. Xing, J.; Xu, H.; Tang, X.; Sheng, X.; Zhan, W.A. DNA vaccine encoding the VAA gene of Vibrio anguillarum induces a pro-tective immune response in flounder. Front. Immunol. 2019, 10, 499. [CrossRef] [PubMed]

15. Li, J.; Tang, L.; Li, S.; Li, G.; Mo, Z. The efficacy and side-effects of oil-based adjuvants emulsified Vibrio anguillarum bivalent inactivated vaccine in turbot (Scophthalmus maximus) under production mode. Aquaculture 2020, 524, 735259. [CrossRef]

16. Schulz, P.; Terech-Majewska, E.; Siwicki, A.K.; Kazuń, B.; Demska-Zakęś, K.; Rożyński, M.; Zakęś, Z. Effect of Different Routes of Vaccination against Aeromonas salmonicida on Rearing Indicators and Survival after an Experimental Challenge of Pikeperch (Sander lucioperca) in Controlled Rearing. Vaccines 2020, 8, 476. [CrossRef]

17. Marana, M.H.; Sepúlveda, D.; Chen, D.; Al-Jubury, A.; Jaafar, R.M.; Kania, P.W.; Henriksen, N.H.; Krossøy, B.; Dalsgaard, I.; Lorenzen, N.; et al. A pentavalent vaccine for rainbow trout in Danish aquaculture. Fish Shellfish Immunol. 2019, 88, 344-351. [CrossRef] [PubMed]

18. Bao, P.; Sun, X.; Liu, Q.; Zhang, Y.; Liu, X. Synergistic effect of a combined live Vibrio anguillarum and Edwardsiella piscicida vaccine in turbot. Fish Shellfish Immunol. 2019, 88, 84-90. [CrossRef]

19. Aly, S.M.; Eissa, A.E.; ElBanna, N.I.; Albutti, A. Efficiency of monovalent and polyvalent Vibrio alginolyticus and Vibrio Parahaemolyticus vaccines on the immune response and protection in gilthead sea bream, Sparus aurata (L.) against vibriosis. Fish Shellfish Immunol. 2021, 111, 145-151. [CrossRef]

20. Martin, S.; Blaney, S.; Houlihan, D.; Secombes, C. Transcriptome response following administration of a live bacterial vaccine in Atlantic salmon (Salmo salar). Mol. Immunol. 2006, 43, 1900-1911. [CrossRef]

21. Zhang, H.; Fei, C.; Wu, H.; Yang, M.; Liu, Q.; Wang, Q.; Zhang, Y. Transcriptome Profiling Reveals Th17-Like Immune Responses Induced in Zebrafish Bath-Vaccinated with a Live Attenuated Vibrio anguillarum. PLoS ONE 2013, 8, e73871. [CrossRef]

22. Braden, L.M.; Whyte, S.K.; Brown, A.B.J.; Van Iderstine, C.; Letendre, C.; Groman, D.; Lewis, J.; Purcell, S.L.; Hori, T.; Fast, M.D. Vaccine-Induced Protection Against Furunculosis Involves Pre-emptive Priming of Humoral Immunity in Arctic Charr. Front. Immunol. 2019, 10, 120. [CrossRef]

23. Lim, J.; Hong, S. Characterization of Aeromonas salmonicida and A. sobria isolated from cultured salmonid fish in Korea and development of a vaccine against furunculosis. J. Fish Dis. 2020, 43, 609-620. [CrossRef] [PubMed]

24. Yang, Y.; Park, J.; You, S.G.; Hong, S. Immuno-stimulatory effects of sulfated polysaccharides isolated from Codium fragile in olive flounder, Paralichthys olivaceus. Fish Shellfish Immunol. 2019, 87, 609-614. [CrossRef] [PubMed]

25. Hong, S.; Li, R.; Xu, Q.; Secombes, C.J.; Wang, T. Two types of TNF- $\alpha$ exist in teleost fish: Phylogeny, expression, and bioactivity analysis of type-II TNF- $\alpha 3$ in rainbow trout Oncorhynchus mykiss. J. Immunol. Res. 2013, 191, 5959-5972. [CrossRef] [PubMed]

26. Kim, J.; Cho, M.; Kim, K.I.; Min, E.Y.; Lim, J.; Hong, S. Transcriptome profiling in head kidney of rainbow trout (Oncorhynchus mykiss) after infection with the low-virulent Nagano genotype of infectious hematopoietic necrosis virus. Arch. Virol. 2021, 166, 1057-1070. [CrossRef]

27. Trapnell, C.; Roberts, A.; Goff, L.; Pertea, G.; Kim, D.; Kelley, D.R.; Pimentel, H.; Salzberg, S.L.; Rinn, J.L.; Pachter, L. Differ-ential gene and transcript expression analysis of RNA-seq experiments with TopHat and Cufflinks. Nat. Protoc. 2012, 7, 562-578. [CrossRef]

28. Romstad, A.B.; Reitan, L.J.; Midtlyng, P.; Gravningen, K.; Evensen, Ø. Antibody responses correlate with antigen dose and in vivo protection for oil-adjuvanted, experimental furunculosis (Aeromonas salmonicida subsp. salmonicida) vaccines in Atlantic salmon (Salmo salar L.) and can be used for batch potency testing of vaccines. Vaccine 2013, 31, 791-796. [CrossRef]

29. Origgi, F.C.; Benedicenti, O.; Segner, H.; Sattler, U.; Wahli, T.; Frey, J. Aeromonas salmonicida type III secretion sys-tem-effectorsmediated immune suppression in rainbow trout (Oncorhynchus mykiss). Fish Shellfish Immunol. 2017, 60, 334-345. [CrossRef]

30. Zhang, Z.; Niu, C.; Storset, A.; Bøgwald, J.; Dalmo, R.A. Comparison of Aeromonas salmonicida resistant and susceptible salmon families: A high immune response is beneficial for the survival against Aeromonas salmonicida challenge. Fish Shellfish Immunol. 2011, 31, 1-9. [CrossRef]

31. Broere, F.; van Eden, W. T Cell Subsets and T Cell-Mediated Immunity. In Nijkamp and Parnham's Principles of Immunopharmacology; Parnham, M.J., Nijkamp, F.P., Rossi, A.G., Eds.; Springer International Publishing: Cham, Switzerland, 2019; pp. 23-35, ISBN 978-3-030-10811-3.

32. Kanhere, A.; Hertweck, A.; Bhatia, U.; Gökmen, M.R.; Perucha, E.; Jackson, I.; Lord, G.M.; Jenner, R.G. T-bet and GATA3 orchestrate Th1 and Th2 differentiation through lineage-specific targeting of distal regulatory elements. Nat. Commun. 2012, 3, 1268. [CrossRef] 
33. Wang, T.; Holland, J.W.; Martin, S.; Secombes, C.J. Sequence and expression analysis of two T helper master transcription factors, T-bet and GATA3, in rainbow trout Oncorhynchus mykiss and analysis of their expression during bacterial and parasitic infection. Fish Shellfish Immunol. 2010, 29, 705-715. [CrossRef]

34. Soleto, I.; Morel, E.; Muñoz-Atienza, E.; Díaz-Rosales, P.; Tafalla, C. Aeromonas salmonicida activates rainbow trout IgM+ B cells signalling through Toll like receptors. Sci. Rep. 2020, 10, 1-12. [CrossRef]

35. Liu, T.; Zhang, L.; Joo, D.; Sun, S.C. NF-кB signaling in inflammation. Signal. Transduct. Target. Ther. 2017, 2, 1-9. [CrossRef] [PubMed]

36. Chen, L.; Deng, H.; Cui, H.; Fang, J.; Zuo, Z.; Deng, J.; Li, Y.; Wang, X.; Zhao, L. Inflammatory responses and inflamma-tionassociated diseases in organs. Oncotarget 2018, 9, 7204. [CrossRef]

37. Caipang, C.M.; Hynes, N.; Puangkaew, J.; Brinchmann, M.F.; Kiron, V. Intraperitoneal vaccination of Atlantic cod, Gadus morhua with heat-killed Listonella anguillarum enhances serum antibacterial activity and expression of immune response genes. Fish Shellfish Immunol. 2008, 24, 314-322. [CrossRef] [PubMed]

38. Lopez-Castejon, G.; Sepulcre, M.P.; Roca, F.J.; Castellana, B.; Planas, J.; Meseguer, J.; Mulero, V. The type II interleukin-1 receptor (IL-1RII) of the bony fish gilthead seabream Sparus aurata is strongly induced after infection and tightly regulated at transcriptional and post-transcriptional levels. Mol. Immunol. 2007, 44, 2772-2780. [CrossRef]

39. Meloni, M.; Candusso, S.; Galeotti, M.; Volpatti, D. Preliminary study on expression of antimicrobial peptides in European sea bass (Dicentrarchus labrax) following in vivo infection with Vibrio anguillarum. A time course experiment. Fish Shellfish Immunol. 2015, 43, 82-90. [CrossRef] [PubMed]

40. Engelsma, M.; Huising, M.O.; van Muiswinkel, W.B.; Flik, G.; Kwang, J.; Savelkoul, H.F.; Kemenade, B.V.-V. Neuroendocrineimmune interactions in fish: A role for interleukin-1. Veter. Immunol. Immunopathol. 2002, 87, 467-479. [CrossRef]

41. Pétrilli, V.; Dostert, C.; Muruve, D.A.; Tschopp, J. The inflammasome: A danger sensing complex triggering innate immunity. Curr. Opin. Immunol. 2007, 19, 615-622. [CrossRef] [PubMed]

42. Zmora, N.; Levy, M.; Pevsner-Fishcer, M.; Elinav, E. Inflammasomes and intestinal inflammation. Mucosal Immunol. 2017, 10, 865-883. [CrossRef]

43. Franchi, L.; Eigenbrod, T.; Muñoz-Planillo, R.; Nuñez, G. The inflammasome: A caspase-1-activation platform that regulates immune responses and disease pathogenesis. Nat. Immunol. 2009, 10, 241-247. [CrossRef]

44. Reis, M.; Vale, A.D.; Pereira, P.; Azevedo, J.E.; Dos Santos, N.M.S. Caspase-1 and IL-1ß Processing in a Teleost Fish. PLoS ONE 2012, 7, e50450. [CrossRef]

45. Sakamaki, K.; Satou, Y. Caspases: Evolutionary aspects of their functions in vertebrates. J. Fish Biol. 2009, 74, 727-753. [CrossRef] [PubMed]

46. Brisse, M.; Ly, H. Comparative Structure and Function Analysis of the RIG-I-Like Receptors: RIG-I and MDA5. Front. Immunol. 2019, 10, 1586. [CrossRef] [PubMed]

47. Zhou, Y.; Lu, L.-F.; Lu, X.-B.; Li, S.; Zhang, Y.-A. Grass carp cGASL negatively regulates fish IFN response by targeting MITA. Fish Shellfish Immunol. 2019, 94, 871-879. [CrossRef] [PubMed]

48. Gong, X.-Y.; Zhang, Q.-M.; Gui, J.-F.; Zhang, Y.-B. SVCV infection triggers fish IFN response through RLR signaling pathway. Fish Shellfish Immunol. 2018, 86, 1058-1063. [CrossRef] [PubMed]

49. Chiu, Y.H.; MacMillan, J.B.; Chen, Z.J. RNA polymerase III detects cytosolic DNA and induces type I interferons through the RIG-I pathway. Cell 2009, 138, 576-591. [CrossRef]

50. Vallejo, A.N.; Miller, N.W.; Harvey, N.E.; Cuchens, M.A.; Warr, G.W.; Clem, L.W. Cellular Pathway(S) of Antigen Processing and Presentation in Fish APC: Endosomal Involvement and Cell-Free Antigen Presentation. Dev. Immunol. 1992, 3, 51-65. [CrossRef]

51. Vinay, D.S.; Kwon, B.S. 4-1BB signaling beyond T cells. Cell. Mol. Immunol. 2011, 8, 281-284. [CrossRef]

52. Nomiyama, H.; Hieshima, K.; Osada, N.; Kato-Unoki, Y.; Otsuka-Ono, K.; Takegawa, S.; Izawa, T.; Yoshizawa, A.; Kikuchi, Y.; Tanase, S.; et al. Extensive expansion and diversification of the chemokine gene family in zebrafish: Identification of a novel chemokine subfamily CX. BMC Genom. 2008, 9, 222. [CrossRef]

53. Alejo, A.; Tafalla, C. Chemokines in teleost fish species. Dev. Comp. Immunol. 2011, 35, 1215-1222. [CrossRef]

54. Bobanga, I.D.; Petrosiute, A.; Huang, A.Y. Chemokines as Cancer Vaccine Adjuvants. Vaccines 2013, 1, 444-462. [CrossRef]

55. Antoniak, S. The coagulation system in host defense. Res. Pr. Thromb. Haemost. 2018, 2, 549-557. [CrossRef] [PubMed]

56. Dunkelberger, J.R.; Song, W.-C. Complement and its role in innate and adaptive immune responses. Cell Res. 2009, 20, 34-50. [CrossRef] [PubMed]

57. Boshra, H.; Li, J.; Sunyer, J. Recent advances on the complement system of teleost fish. Fish Shellfish Immunol. 2006, 20, 239-262. [CrossRef] [PubMed]

58. Løvoll, M.; Fischer, U.; Mathisen, G.S.; Bøgwald, J.; Ototake, M.; Dalmo, R.A. The C3 subtypes are differentially regulated after immunostimulation in rainbow trout, but head kidney macrophages do not contribute to C3 transcription. Veter. Immunol. Immunopathol. 2007, 117, 284-295. [CrossRef] [PubMed]

59. Fu, Y.-W.; Zhu, C.-K.; Zhang, Q.-Z. Molecular characterization and expression analysis of complement component C3 in southern catfish (Silurus meridionalis) and a whole mount in situ hybridization study on its ontogeny. Fish Shellfish Immunol. 2018, 84, 865-875. [CrossRef] [PubMed] 
60. Meng, X.; Shen, Y.; Wang, S.; Xu, X.; Dang, Y.; Zhang, M.; Li, L.; Zhang, J.; Wang, R.; Li, J. Complement component 3 (C3): An important role in grass carp (Ctenopharyngodon idella) experimentally exposed to Aeromonas hydrophila. Fish Shellfish Immunol. 2019, 88, 189-197. [CrossRef] [PubMed]

61. Løvoll, M.; Dalmo, R.A.; Bøgwald, J. Extrahepatic synthesis of complement components in the rainbow trout (Oncorhynchus mykiss). Fish Shellfish Immunol. 2007, 23, 721-731. [CrossRef]

62. Fujita, T.; Matsushita, M.; Endo, Y. The lectin-complement pathway-its role in innate immunity and evolution. Immunol. Rev. 2004, 198, 185-202. [CrossRef] [PubMed]

63. Hou, Z.S.; Xin, Y.R.; Yang, X.D.; Zeng, C.; Zhao, H.K.; Liu, M.Q.; Zhang, M.Z.; Daniel, J.G.; Li, J.F.; Wen, H.S. Transcriptional profiles of genes related to stress and immune response in Rainbow trout (Oncorhynchus mykiss) symptomatically or asymptomatically infected with Vibrio anguillarum. Front. Immunol. 2021, 12, 639489. [CrossRef] [PubMed] 